\title{
Trends in risk factors for cardiovascular disease in Canada: temporal, socio-demographic and geographic factors
}

\author{
Douglas S. Lee MD PhD, Maria Chiu MSc, Douglas G. Manuel MD MSc, Karen Tu MD MSc, \\ Xuesong Wang MSc, Peter C. Austin PhD, Michelle Y. Mattern PhD, Tezeta F. Mitiku BSc, \\ Lawrence W. Svenson BGS, Wayne Putnam MD, William M. Flanagan BM, Jack V. Tu MD PhD, \\ for the Canadian Cardiovascular Outcomes Research Team
}

\section{ABSTRACT}

Background: Temporal trends in risk factors for cardiovascular disease and the impact of socio-economic status on these risk factors remain unclear.

Methods: Using data from the National Population Health Survey and the Canadian Community Health Survey, we examined national trends in heart disease, hypertension, diabetes mellitus, obesity and smoking prevalence from 1994 to 2005, adjusting for age and sex. We stratified data by income adequacy category, body mass index and region of residence.

Results: An estimated 1.29 million Canadians reported having heart disease in 2005, representing increases of $19 \%$ for men and $2 \%$ for women, relative to 1994 . Heart disease increased significantly in the lowest income category (by $27 \%$ ), in the lower middle income category (by $37 \%$ ) and in the upper middle income category (by 12\%); however, it increased by only $6 \%$ in the highest income group. Diabetes increased in all but the highest income group: by $56 \%$ in the lowest income group, by $93 \%$ in the lower middle income group and by $59 \%$ in the upper middle income group. Hypertension increased in all income groups: by $85 \%$ in the lowest income group, by $80 \%$ in the lower middle income group, by $91 \%$ in the upper middle income group and by $117 \%$ in the highest income group. Obesity also increased in all income groups: by $20 \%$ in the lowest income group, by $25 \%$ in the lower middle income group, by $33 \%$ in the upper middle income group and by $37 \%$ in the highest income group. In addition to socio-economic status, obesity and overweight also modified the trends in risk factors. Diabetes increased to a greater extent among obese participants (61\% increase) and overweight participants ( $25 \%$ increase), as did hypertension, which increased by $80 \%$ among obese individuals and by $74 \%$ among overweight individuals. Trends in diabetes, hypertension and obesity were consistent for all provinces.
Interpretation: During the study period, heart disease, hypertension, diabetes and obesity increased for all or most income groups in Canada. Further interventions supporting modification of lifestyle and risk factors are needed to prevent future cardiovascular disease.

Une version française de ce résumé est disponible à l'adresse www.cmaj.ca/cgi/content/full/cmaj.081629/DC1

Cite as CMAJ 2009. DOI:10.1503/cmaj.081629

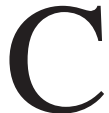
ardiovascular disease is a major cause of premature death, admission to hospital and disability in developed nations. Deaths due to cardiovascular disease have declined over time in Canada, ${ }^{1}$ and similar improvements in mortality have been reported in the United States. ${ }^{2}$ Although these data are encouraging, there is a paucity of knowledge about national trends in the risk factors that lead to cardiovascular disease. Knowledge of risk factors and their trends in younger populations in whom clinically evident heart disease has not yet developed will largely determine the future incidence of cardiovascular disease. The importance of risk factors is further underscored by the substantial reductions in coronary artery disease that can be achieved by primary prevention. ${ }^{3}$

From the Institute for Clinical Evaluative Sciences (Lee, Chiu, Manuel, K. Tu, Wang, Austin, Mattern, Mitiku, J. Tu), Toronto, Ont.; the Division of Cardiology (Lee) and the Department of Family Medicine (K. Tu), University Health Network, Toronto, Ont.; the Institute of Medical Science (Chiu) and the Department of Health Policy, Management and Evaluation (Austin, J. Tu), University of Toronto, Toronto, Ont.; the Department of Community Health and Epidemiology (Mitiku), Queen's University, Kingston, Ont.; Alberta Health and Wellness (Svenson), Edmonton, Alta.; the School of Public Health (Svenson), University of Alberta, Edmonton, Alta.; Community Health Services (Svenson), University of Calgary, Calgary, Alta.; the Department of Family Medicine (Putnam), Dalhousie University, Halifax, NS; Statistics Canada (Flanagan), Ottawa, Ont.; and the Department of Medicine (J. Tu), Sunnybrook Health Sciences Centre, Toronto, Ont. 
Table 1: Statistics Canada's 4-group categorization of income adequacy

\begin{tabular}{llll}
\hline \multirow{2}{*}{$\begin{array}{l}\text { Category of } \\
\text { income adequacy }\end{array}$} & \multicolumn{3}{c}{ Family size; total household income, $\$$} \\
\cline { 2 - 4 } & 1 or 2 people & 3 or 4 people & $\geq 5$ people \\
\hline Lowest (Q1) & $<15000$ & $<20000$ & $<30000$ \\
\hline Lower middle (Q2) & $15000-29999$ & $20000-39999$ & $30000-59999$ \\
Upper middle (Q3) & $30000-59999$ & $40000-79999$ & $60000-79999$ \\
\hline Highest (Q4) & $\geq 60000$ & $\geq 80000$ & $\geq 80000$ \\
\hline
\end{tabular}

$(n=17$ 626) and $1996(n=73$ 402) and the Canadian Community Health Survey in $2001(n=131535), 2003(n=$ $135573)$ and $2005(n=132$ 947). The respondents were drawn from a Canadian population ranging from 29.0 million ( 24.2 million aged $\geq 12$ years) in 1994 to a population of 32.3 million (27.9 million aged $\geq 12$ years) in 2005 . We stratified participants by sex and categorized them by age group (12-34, 35 $49,50-64,65-74$ and $\geq 75$ years), to

Few studies have comprehensively examined the range of risk factors and their trends over time and the related demographic, socio-economic and geographic factors that influence these trends. In this study, we examined the prevalence of risk factors among Canadians aged 12 years or older, from the perspective of socio-demographic correlates, regional variations and temporal trends. We examined trends in hypertension, diabetes mellitus, smoking and obesity, which are modifiable cardiovascular risk factors and/or chronic diseases. The risk factors evaluated were of interest because they can be modified by changes in both health policy and an individual's lifestyle.

We explored important patient strata relevant to the epidemiology of cardiovascular disease, including sex, age, socio-economic status and overweight or obesity status, to determine how these factors influenced trends in risk factors over time. For socio-economic status, we used the income adequacy categories developed by Statistics Canada, which represent a measure of total family income that accounts for the size of the family unit. We hypothesized an increasing burden of cardiovascular disease risk factors overall and clustering of risk, particularly among those with lower socioeconomic status or higher body mass index (BMI).

\section{Methods}

\section{Data sources}

We used data on risk factors from the cross-sectional National Population Health Survey of 1994 and $1996^{4}$ and the Canadian Community Health Survey, cycles 1.1 (in 2001), 2.1 (in 2003) and 3.1 (in 2005). ${ }^{5}$ Statistics Canada conducted all of these surveys, which were designed to provide reliable estimates of the health of Canadians. The Canadian Community Health Survey replaced the cross-sectional National Population Health Survey in 2001. Although the proportion of surveys conducted in person and by telephone varied, the quality of the data collection methods remained consistent across survey cycles. ${ }^{4-6}$ Moreover, each survey used a consistent, multistage, stratified cluster sampling strategy, as described in detail elsewhere. ${ }^{4,5,7}$ Populations on Aboriginal reserves and Canadian Forces Bases were not included in the surveys.

\section{Study sample}

We analyzed data for people aged 12 years or older who participated in the National Population Health Surveys in 1994 allow for separation of younger participants into age groupings different from those used in previous analyses. We also stratified participants according to socio-economic status, using Statistics Canada's 4-group parsimonious categorization of income adequacy, which is based on total annual household income and number of persons in the family unit (Table 1). ${ }^{8}$

\section{Heart disease and risk factors for cardiovascular disease}

Heart disease and all risk factors had to have been diagnosed by a physician but were self-reported by the patient. We defined patients with diabetes as all those who had received a diagnosis of this disease from a physician, whether or not they were receiving treatment with insulin or oral hypoglycemic medications. We defined respondents who had diabetes only during pregnancy as not having diabetes. We defined patients with hypertension as all those who had received a diagnosis of this condition from a physician, irrespective of antihypertensive treatment. We defined obesity as a BMI of 30 or greater, with BMI being determined from participants' self-reported height and weight. We defined current smoking as daily or occasional consumption of at least 1 cigarette.

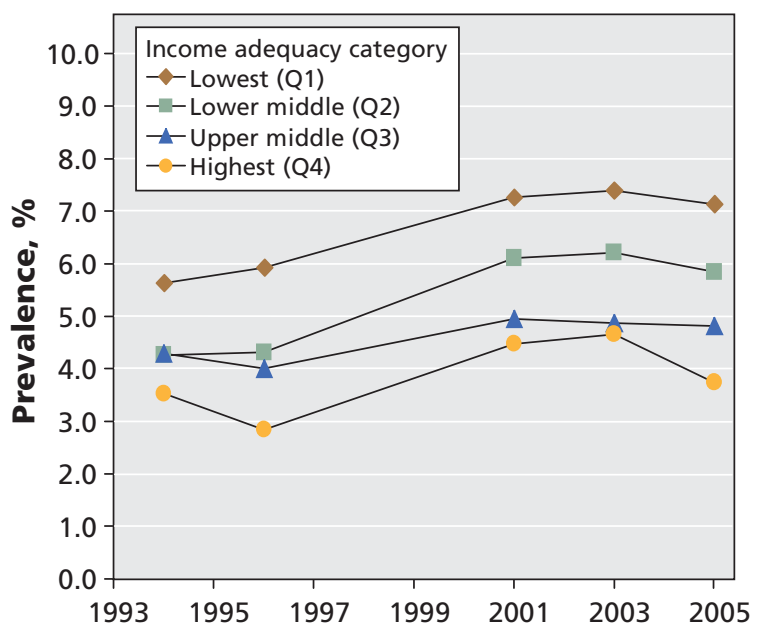

Figure 1: Age- and sex-adjusted trends in heart disease from 1994 to 2005 , stratified by income adequacy category. 


\section{Regional variations}

We determined regional prevalence of hypertension, diabetes, current smoking, obesity, low physical activity and low income adequacy for provincial health regions according to each respondent's postal code. ${ }^{9}$ We determined the prevalence of physical inactivity solely for the regional analysis, using the Physical Activity Index, as described previously..$^{10}$ We determined the sum total of the above risk factors that exceeded the Canadian average by more than $10 \%$ at the regional level, with a minimum of 0 and a maximum of 6 risk factors per region. ${ }^{10}$

\section{Statistical analyses}

We examined the prevalence of risk factors for the period 1994 to 2005, adjusting for survey sampling weights, and evaluated these data using linear regression analysis. We determined the percent increase or decrease in rates in the last year of the study period relative to the baseline prevalence in 1994. We standardized the time-trend analyses by age and sex, and we standardized sex-specific analyses by age using the 1991 Canadian Census population. We also examined time trends in risk factors stratified by BMI. We considered $p$ values of less than 0.05 to be statistically significant. We performed these analyses using the master files at the Statistics Canada offices in Ottawa, Ontario.

\section{Results}

\section{Study sample}

In 1994 the mean age of the sample population of survey respondents was 41 (standard deviation [SD] 18) years; 49.2\% of the respondents were male. In 2005, the mean age was 43 (SD 19) years; $49.3 \%$ were male. The majority of respondents were white in both 1994 (89.7\%) and 2005 (80.9\%).

\section{Heart disease}

In 1994 the national age- and sex-adjusted prevalence of heart disease was $3.6 \%$ among males and $2.8 \%$ among females; these prevalences increased to $4.3 \%$ of males and $2.9 \%$ of females in 2005 . These changes represented relative increases of $19 \%$ for males and 2\% for females. Early-onset heart disease (at age $<55$ years for males and $<65$ years for females) increased nonsignificantly from $0.9 \%$ to $1.1 \%$ among males $(p=0.07)$ and from $1.3 \%$ to $1.5 \%$ among females $(p=0.23)$. In 2005, an estimated 1.29 million Canadians had heart disease (725000 males and 565000 females), which represented an increase of 380000 patients over 1994. Rates of heart disease were higher among participants with lower socio-economic status than among their higher-income counterparts during each study year (Figure $1)$. The prevalence of heart disease increased significantly in the lowest $(p=0.022)$ and lower middle $(p=0.035)$ income categories. Compared with 1994, the prevalence of heart disease in 2005 represented an increase of $27 \%$ in the lowest income category, $37 \%$ in the lower middle income category, $12 \%$ in the upper middle income category and $6 \%$ in the highest income category.

\section{Trends in risk factors}

National trends in the prevalence of risk factors among males, females and both sexes are shown in Table 2. The prevalence of diabetes and obesity increased significantly over the study period, whereas smoking rates declined. The prevalence of hypertension nearly doubled among both males and females. The prevalence of cardiovascular risk factors increased even among younger respondents (Table 3 ). Although the prevalence of hypertension was higher among older persons, the

Table 2: Age- and sex-adjusted prevalence of risk factors for survey respondents aged 12 years and older, from 1994 to 2005

\begin{tabular}{|c|c|c|c|c|c|c|c|}
\hline \multirow[b]{2}{*}{ Risk factor } & \multicolumn{5}{|c|}{ Year; prevalence, \% } & \multirow{2}{*}{$\begin{array}{c}\text { Relative change } \\
\text { from } 1994 \text { to } 2005, \%\end{array}$} & \multirow[b]{2}{*}{$p$ value } \\
\hline & 1994 & 1996 & 2001 & 2003 & 2005 & & \\
\hline \multicolumn{8}{|l|}{ Both sexes* } \\
\hline Hypertension & 8.2 & 9.0 & 10.0 & 11.0 & 14.6 & 77 & 0.042 \\
\hline Diabetes mellitus & 2.5 & 2.6 & 3.2 & 3.5 & 3.6 & 45 & $<0.001$ \\
\hline Current smoking & 24.4 & 23.0 & 21.7 & 19.2 & 18.2 & -25 & 0.005 \\
\hline Obesity & 9.5 & 8.8 & 10.6 & 10.8 & 11.2 & 18 & 0.030 \\
\hline \multicolumn{8}{|l|}{ Malest } \\
\hline Hypertension & 7.3 & 8.3 & 9.4 & 10.6 & 14.0 & 92 & 0.031 \\
\hline Diabetes mellitus & 2.7 & 3.0 & 3.5 & 3.8 & 4.1 & 52 & $<0.001$ \\
\hline Current smoking & 25.5 & 24.7 & 23.2 & 20.8 & 19.7 & -23 & 0.006 \\
\hline Obesity & 9.4 & 9.4 & 11.3 & 11.7 & 12.3 & 31 & 0.002 \\
\hline \multicolumn{8}{|l|}{ Femalest } \\
\hline Hypertension & 8.9 & 9.5 & 10.4 & 11.2 & 14.9 & 67 & 0.06 \\
\hline Diabetes mellitus & 2.3 & 2.2 & 2.9 & 3.1 & 3.2 & 37 & 0.006 \\
\hline Current smoking & 23.3 & 21.3 & 20.1 & 17.7 & 16.7 & -28 & 0.006 \\
\hline Obesity & 9.6 & 8.2 & 9.9 & 9.9 & 10.1 & 6 & 0.23 \\
\hline
\end{tabular}

*Age- and sex-adjusted rates were standardized to estimates of the 1991 Canadian population.

†Age-adjusted rates were standardized to estimates of the 1991 Canadian population. 
increase in prevalence over time was greater among younger individuals $(p$ for interaction $=0.027$ ). The prevalence of diabetes $(p$ for age-diabetes interaction $=0.16$ ), obesity $(p$ for age-obesity interaction $=0.91$ ) and multiple risk factors (see Table 4) increased among males and females of all ages, whereas smoking rates decreased ( $p$ for age-smoking interaction $=0.50)$.
Trends in risk factors by income adequacy category

The burden of risk factors was higher among those of lower socio-economic status. Unadjusted rates of heart disease and risk factors are shown in Table 5 and age- and sex-adjusted rates in Figure 2. In 2005, the age- and sex-adjusted prevalence of physician-diagnosed hypertension was $24.0 \%$ in the lowest income group, $21.0 \%$ in the lower middle income

Table 3: Prevalence of risk factors, by age categories, from 1994 to 2005 (part 1)

\begin{tabular}{|c|c|c|c|c|c|c|c|}
\hline \multirow[b]{2}{*}{ Sex; age, yr } & \multicolumn{5}{|c|}{ Year; prevalence, \% } & \multirow{2}{*}{$\begin{array}{c}\text { Relative change } \\
\text { from } 1994 \text { to } 2005, \%\end{array}$} & \multirow[b]{2}{*}{$p$ value } \\
\hline & 1994 & 1996 & 2001 & 2003 & 2005 & & \\
\hline \multicolumn{8}{|c|}{ Hypertension } \\
\hline \multicolumn{8}{|l|}{ Both sexes } \\
\hline $12-34$ & 1.0 & 1.1 & 1.8 & 1.8 & 3.7 & 261 & 0.07 \\
\hline $35-49$ & 5.6 & 6.2 & 7.7 & 8.5 & 12.8 & 127 & 0.045 \\
\hline $50-64$ & 19.8 & 21.8 & 22.9 & 25.7 & 32.0 & 61 & 0.043 \\
\hline $65-74$ & 32.9 & 35.2 & 38.0 & 41.5 & 50.1 & 52 & 0.030 \\
\hline$\geq 75$ & 34.6 & 38.7 & 41.5 & 44.9 & 55.6 & 61 & 0.032 \\
\hline \multicolumn{8}{|l|}{ Males } \\
\hline $12-34$ & 1.0 & 1.1 & 1.8 & 2.0 & 3.5 & 264 & 0.033 \\
\hline $35-49$ & 5.6 & 6.4 & 8.2 & 9.5 & 13.2 & 135 & 0.020 \\
\hline $50-64$ & 18.1 & 20.5 & 21.5 & 25.1 & 32.1 & 77 & 0.045 \\
\hline $65-74$ & 30.0 & 33.0 & 35.3 & 38.2 & 47.4 & 58 & 0.037 \\
\hline$\geq 75$ & 27.1 & 32.1 & 35.9 & 38.3 & 49.9 & 84 & 0.027 \\
\hline \multicolumn{8}{|l|}{ Females } \\
\hline $12-34$ & 1.1 & 1.1 & 1.8 & 1.6 & 4.0 & 258 & 0.13 \\
\hline $35-49$ & 5.7 & 6.0 & 7.2 & 7.5 & 12.5 & 120 & 0.09 \\
\hline $50-64$ & 21.5 & 23.0 & 24.3 & 26.3 & 31.8 & 48 & 0.041 \\
\hline $65-74$ & 35.7 & 37.3 & 40.6 & 44.7 & 52.6 & 47 & 0.025 \\
\hline$\geq 75$ & 41.9 & 45.1 & 47.0 & 51.4 & 61.2 & 46 & 0.040 \\
\hline \multicolumn{8}{|l|}{ Diabetes } \\
\hline \multicolumn{8}{|l|}{ Both sexes } \\
\hline $12-34$ & 0.4 & 0.5 & 0.6 & 0.7 & 0.7 & 70 & 0.003 \\
\hline $35-49$ & 1.6 & 1.7 & 2.5 & 2.5 & 2.6 & 64 & 0.007 \\
\hline $50-64$ & 5.3 & 6.0 & 7.1 & 8.3 & 8.3 & 58 & 0.002 \\
\hline $65-74$ & 11.2 & 10.0 & 13.0 & 14.2 & 14.7 & 32 & 0.021 \\
\hline$\geq 75$ & 11.7 & 11.9 & 12.9 & 12.9 & 15.0 & 28 & 0.043 \\
\hline \multicolumn{8}{|l|}{ Males } \\
\hline $12-34$ & $-*$ & 0.5 & 0.6 & 0.6 & 0.7 & 78 & 0.014 \\
\hline $35-49$ & 1.3 & 1.6 & 2.5 & 2.4 & 2.7 & 112 & 0.004 \\
\hline $50-64$ & 6.1 & 7.4 & 8.2 & 9.7 & 9.7 & 59 & 0.007 \\
\hline $65-74$ & 12.5 & 11.2 & 14.7 & 16.4 & 17.3 & 38 & 0.018 \\
\hline$\geq 75$ & 13.0 & 14.6 & 14.8 & 14.0 & 16.8 & 29 & 0.15 \\
\hline \multicolumn{8}{|l|}{ Females } \\
\hline $12-34$ & $-*$ & 0.5 & 0.7 & 0.7 & 0.8 & 63 & 0.002 \\
\hline $35-49$ & 1.8 & 1.8 & 2.5 & 2.6 & 2.4 & 31 & 0.037 \\
\hline $50-64$ & 4.5 & 4.6 & 6.1 & 7.0 & 7.0 & 56 & 0.003 \\
\hline $65-74$ & 9.8 & 8.8 & 11.3 & 12.0 & 12.3 & 25 & 0.029 \\
\hline$\geq 75$ & 10.4 & 9.2 & 10.9 & 11.8 & 13.1 & 26 & 0.05 \\
\hline
\end{tabular}


Table 3: Prevalence of risk factors, by age categories, from 1994 to 2005 (part 2)

\begin{tabular}{|c|c|c|c|c|c|c|c|}
\hline \multirow[b]{2}{*}{ Sex; age, yr } & \multicolumn{5}{|c|}{ Year; prevalence, \% } & \multirow{2}{*}{$\begin{array}{l}\text { Relative change from } \\
1994 \text { to } 2005, \%\end{array}$} & \multirow[b]{2}{*}{$p$ value } \\
\hline & 1994 & 1996 & 2001 & 2003 & 2005 & & \\
\hline \multicolumn{8}{|l|}{ Smoking } \\
\hline \multicolumn{8}{|l|}{ Both sexes } \\
\hline $12-34$ & 32.0 & 29.8 & 28.1 & 24.7 & 22.9 & -28 & 0.006 \\
\hline $35-49$ & 33.7 & 32.1 & 31.2 & 27.6 & 26.6 & -21 & 0.014 \\
\hline $50-64$ & 27.2 & 25.0 & 23.5 & 21.5 & 20.6 & -24 & 0.003 \\
\hline $65-74$ & 17.5 & 17.3 & 14.6 & 13.3 & 13.0 & -26 & 0.002 \\
\hline$\geq 75$ & 10.1 & 11.4 & 8.7 & 7.5 & 7.4 & -27 & 0.037 \\
\hline \multicolumn{8}{|l|}{ Males } \\
\hline $12-34$ & 31.2 & 30.8 & 29.9 & 26.8 & 25.0 & -20 & 0.028 \\
\hline $35-49$ & 37.1 & 35.2 & 33.9 & 30.2 & 29.0 & -22 & 0.010 \\
\hline $50-64$ & 30.8 & 28.0 & 25.0 & 22.8 & 21.7 & -30 & $<0.001$ \\
\hline $65-74$ & 19.6 & 19.9 & 15.1 & 13.7 & 13.4 & -32 & 0.006 \\
\hline$\geq 75$ & 11.8 & 13.3 & 9.9 & 7.7 & 7.5 & -37 & 0.027 \\
\hline \multicolumn{8}{|l|}{ Females } \\
\hline $12-34$ & 32.7 & 28.8 & 26.3 & 22.6 & 20.7 & -37 & 0.004 \\
\hline $35-49$ & 30.5 & 29.1 & 28.6 & 25.1 & 24.2 & -21 & 0.022 \\
\hline $50-64$ & 23.7 & 22.0 & 22.0 & 20.2 & 19.6 & -18 & 0.022 \\
\hline $65-74$ & 15.5 & 14.8 & 14.2 & 12.9 & 12.5 & -19 & 0.005 \\
\hline$\geq 75$ & 8.3 & 9.5 & 7.5 & 7.4 & 7.3 & -13 & 0.10 \\
\hline \multicolumn{8}{|l|}{ Obesity } \\
\hline \multicolumn{8}{|l|}{ Both sexes } \\
\hline $12-34$ & 7.4 & 6.6 & 8.5 & 8.8 & 8.8 & 19 & 0.046 \\
\hline $35-49$ & 13.5 & 12.5 & 15.2 & 14.9 & 16.2 & 20 & 0.040 \\
\hline $50-64$ & 17.2 & 16.3 & 18.9 & 19.6 & 19.9 & 15 & 0.023 \\
\hline $65-74$ & 15.4 & 15.0 & 16.6 & 17.0 & 17.6 & 14 & 0.011 \\
\hline$\geq 75$ & 9.8 & 8.6 & 10.4 & 10.8 & 11.7 & 19 & 0.07 \\
\hline \multicolumn{8}{|l|}{ Males } \\
\hline $12-34$ & 7.2 & 7.1 & 9.6 & 10.4 & 10.0 & 40 & 0.014 \\
\hline $35-49$ & 13.6 & 14.2 & 16.8 & 16.4 & 18.6 & 37 & 0.009 \\
\hline $50-64$ & 17.9 & 16.8 & 19.5 & 20.2 & 21.0 & 17 & 0.026 \\
\hline $65-74$ & 13.9 & 15.5 & 16.1 & 16.2 & 17.4 & 25 & 0.022 \\
\hline$\geq 75$ & 8.8 & 7.5 & 8.7 & 10.4 & 11.0 & 25 & 0.09 \\
\hline \multicolumn{8}{|l|}{ Females } \\
\hline $12-34$ & 7.6 & 6.1 & 7.4 & 7.3 & 7.6 & $<1$ & 0.51 \\
\hline $35-49$ & 13.3 & 10.8 & 13.7 & 13.4 & 13.7 & 4 & 0.34 \\
\hline $50-64$ & 16.6 & 15.9 & 18.3 & 18.9 & 18.8 & 13 & 0.025 \\
\hline $65-74$ & 16.9 & 14.4 & 17.1 & 17.8 & 17.8 & 6 & 0.21 \\
\hline$\geq 75$ & 10.9 & 9.7 & 12.1 & 11.1 & 12.3 & 14 & 0.16 \\
\hline
\end{tabular}

*Data value too small to report.

group, $20.8 \%$ in the upper middle income group and $18.6 \%$ in the highest income group ( $p$ for trend $=0.046$ ). Diabetes also exhibited an inverse gradient according to socio-economic status: $7.5 \%$ in the lowest income group, $6.5 \%$ in the lower middle income group, $5.0 \%$ in the higher middle income group and 3.4\% in the highest income group ( $p$ for trend $=$ 0.006). Obesity exhibited a similar gradient according to income, with age- and sex-adjusted prevalences of $16.9 \%$ in the lowest income group, $16.5 \%$ in the lower middle income group, $16.5 \%$ in the higher middle income group and $13.5 \%$ 
Table 4: Percentage of survey respondents aged 12 years and older with 2 or more risk factors over time, by age and sex

\begin{tabular}{|c|c|c|c|c|c|c|c|}
\hline \multirow[b]{2}{*}{ Sex; age group, yr } & \multicolumn{5}{|c|}{ Year; prevalence of $\geq 2$ risk factors, $\%$} & \multirow{2}{*}{$\begin{array}{l}\text { Relative change } \\
\text { from } 1994 \text { to } 2005, \%\end{array}$} & \multirow[b]{2}{*}{$p$ value } \\
\hline & 1994 & 1996 & 2001 & 2003 & 2005 & & \\
\hline \multicolumn{8}{|l|}{ Males } \\
\hline $12-34$ & 3.3 & 2.9 & 4.1 & 4.5 & 4.6 & 42 & 0.015 \\
\hline $35-49$ & 8.0 & 8.1 & 9.8 & 9.5 & 12.3 & 53 & 0.043 \\
\hline $50-64$ & 14.5 & 15.3 & 16.4 & 18.2 & 20.6 & 42 & 0.019 \\
\hline $65-74$ & 18.2 & 18.1 & 19.2 & 20.4 & 24.8 & 37 & 0.08 \\
\hline$\geq 75$ & 12.7 & 14.2 & 14.1 & 14.2 & 18.9 & 48 & 0.15 \\
\hline Overall* & 6.7 & 6.8 & 7.8 & 8.2 & 9.7 & 45 & 0.018 \\
\hline \multicolumn{8}{|l|}{ Females } \\
\hline $12-34$ & 3.7 & 2.6 & 3.3 & 3.3 & 4.1 & 12 & 0.43 \\
\hline $35-49$ & 7.2 & 5.8 & 8.1 & 7.1 & 9.4 & 31 & 0.19 \\
\hline $50-64$ & 14.0 & 12.8 & 15.8 & 17.0 & 18.6 & 33 & 0.021 \\
\hline $65-74$ & 18.7 & 15.6 & 19.9 & 21.8 & 24.3 & 30 & 0.06 \\
\hline$\geq 75$ & 14.5 & 14.2 & 15.4 & 17.0 & 20.5 & 41 & 0.06 \\
\hline Overall* & 6.8 & 5.7 & 7.2 & 7.3 & 8.7 & 28 & 0.09 \\
\hline
\end{tabular}

*Overall values were age-standardized to 1991 estimates of the Canadian population.

in the highest income group in 2005; these trends were consistent in other years (all $p$ values for trend $<0.001$ ). Smoking rates were higher among those of lower socio-economic status, with age- and sex-adjusted smoking prevalence of $35.8 \%$ in the lowest income group, $29.9 \%$ in the lower middle income group, $24.8 \%$ in the higher middle income group and $19.1 \%$ for the highest income group; trends were similar in other years ( $p$ for trend $<0.001)$.

The relative increases in the prevalence of diabetes were $56 \%$ in the lowest income group $(p=0.004), 93 \%$ in the lower middle income group $(p<0.001)$ and $59 \%$ in the upper middle income group $(p=0.015)$; there was no significant increase in the highest income category $(p=0.21)$. Obesity increased by $20 \%$ in the lowest income group $(p=0.002)$, $25 \%$ in the lower middle income group $(p=0.005), 33 \%$ in the upper middle income group $(p=0.019)$ and $37 \%$ in the highest income group $(p=0.018)$. There was a significant interaction between income and time for diabetes $(p=0.009)$ and for obesity $(p<0.001)$, which suggests that there were differential increases over time. The relative increases in hypertension were $85 \%$ in the lowest income group ( $p=$ $0.093), 80 \%$ in the lower middle income group $(p=0.016)$, $91 \%$ in the upper middle income group $(p=0.037)$ and $117 \%$ in the highest income group $(p=0.030)$. Smoking decreased by $16 \%$ in the lowest income group $(p=0.053)$, by $11 \%$ in the lower middle income group $(p=0.097)$, by $12 \%$ in the upper middle income group $(p=0.039)$ and by $17 \%$ in the highest income group $(p=0.39)$. There was no interaction between income and time for hypertension $(p=0.97)$ or for smoking $(p=0.46)$. The absolute age- and sex-adjusted rates of hypertension and obesity increased consistently across all income groups, whereas diabetes increased only in the lowest 3 income groups (Figure 2).

\section{Trends in risk factors by BMI}

We explored further the trends in risk factors according to BMI, determining both unadjusted rates (Table 4) and age- and sexadjusted results (Figure 3). Within each year, hypertension was more prevalent among those with a higher BMI (all $p<0.001$ ). From 1994 to 2005, the prevalence of hypertension increased significantly (by $80 \%$ ) only among those with a BMI of 30 or greater ( $p$ for time interaction $=0.026$ ). The increase in hypertension over time was $78 \%(p=0.06)$ among those with a BMI of less than 25 and $74 \%(p=0.05)$ among those with a BMI of 25-29.9. Smoking rates decreased consistently in all weight groups over time (all $p<0.05$ ). The prevalence of diabetes increased most markedly among obese individuals $(61 \%$ increase from 1994 to 2005, $p=0.002$ ). There were smaller increases in diabetes among those with a BMI of less than 25 $(27 \%)$ and 25-29.9 $(25 \%)$ ( $p$ for time interaction $=0.01)$.

\section{Provincial trends and regional variations}

Overall, provincial trends for risk factors were consistent with national trends, although variations were evident (Table 6). In 2005, hypertension was most prevalent in New Brunswick, followed by Nova Scotia, and Newfoundland and Labrador. Although Alberta had one of the lowest prevalence rates of hypertension, it also had the greatest increase in this risk factor over time, by $98 \%$ from 1994 to 2005 . The prevalence of diabetes was highest in Newfoundland and Labrador, followed by Nova Scotia and Prince Edward Island. The prevalence of diabetes increased most in New Brunswick (by 79\%). Obesity was most prevalent in Newfoundland and Labrador, followed by New Brunswick and Prince Edward Island. The greatest increase in the prevalence of obesity (by 50\%) occurred in Newfoundland and Labrador. Smoking rates were lowest in British Columbia and highest in Quebec. Of the 125 regions in 
Table 5: Prevalence of heart disease and its risk factors by categories of income and body mass index (BMI)

\begin{tabular}{|c|c|c|c|c|c|}
\hline \multirow{2}{*}{$\begin{array}{l}\text { Year; income or } \\
\text { BMI category }\end{array}$} & \multicolumn{5}{|c|}{ Condition or risk factor; prevalence, $\%$ * } \\
\hline & Heart disease & Hypertension & Diabetes & Smoking & Obesity \\
\hline \multicolumn{6}{|l|}{ Income category } \\
\hline \multicolumn{6}{|l|}{1994} \\
\hline Lowest (Q1) & 6.6 & 15.4 & 5.6 & 39.7 & 14.3 \\
\hline Lower middle (Q2) & 5.2 & 13.8 & 4.0 & 32.2 & 13.4 \\
\hline Upper middle (Q3) & 3.5 & 9.8 & 2.6 & 29.3 & 12.9 \\
\hline Highest (Q4) & 2.3 & 7.3 & 2.3 & 23.5 & 11.0 \\
\hline$p$ for trend & 0.002 & 0.012 & 0.031 & 0.014 & 0.035 \\
\hline \multicolumn{6}{|l|}{2005} \\
\hline Lowest (Q1) & 9.2 & 29.3 & 9.1 & 33.0 & 17.7 \\
\hline Lower middle (Q2) & 8.7 & 27.8 & 8.6 & 26.6 & 17.1 \\
\hline Upper middle (Q3) & 5.2 & 22.3 & 5.5 & 24.4 & 17.0 \\
\hline Highest (Q4) & 2.9 & 17.0 & 3.2 & 20.0 & 14.6 \\
\hline$p$ for trend & 0.034 & 0.024 & 0.032 & 0.018 & 0.11 \\
\hline \multicolumn{6}{|l|}{ BMI category } \\
\hline \multicolumn{6}{|l|}{1994} \\
\hline$<25$ & 2.9 & 6.1 & 1.7 & 30.9 & NA \\
\hline $25-29$ & 4.6 & 13.1 & 3.8 & 28.3 & NA \\
\hline$\geq 30$ & 6.1 & 20.5 & 7.2 & 27.2 & NA \\
\hline$p$ for trend & 0.008 & 0.010 & 0.08 & 0.14 & \\
\hline \multicolumn{6}{|l|}{2005} \\
\hline$<25$ & 3.5 & 12.0 & 2.4 & 22.8 & NA \\
\hline $25-29$ & 5.7 & 24.7 & 5.7 & 21.3 & NA \\
\hline$\geq 30$ & 7.7 & 36.2 & 12.4 & 20.4 & NA \\
\hline$p$ for trend & 0.01 & 0.019 & 0.13 & 0.07 & \\
\hline
\end{tabular}

Note: NA = not applicable.

*Unless indicated otherwise.

Canada for which data were available, $73(58 \%)$ had 3 or more risk factors that exceeded the national average by $10 \%$ or more, and $45(36 \%)$ had 4 or more risk factors that exceeded the national average by $10 \%$ or more (Figure 4 ).

\section{Estimated number of Canadians with risk factors}

On the basis of the weighted risk factor data, we estimated that in 2005, an estimated 2.4 million men and 2.8 million women had physician-diagnosed hypertension, 710000 men and 610000 women had diabetes, and 2.1 million men and 1.7 million women had obesity. Although smoking declined over the 10-year study period, we estimated that there were still 3.2 million men and 2.7 million women who smoked in Canada.

\section{Interpretation}

In this national study, we found that heart disease and the risk factors hypertension, diabetes and obesity were increasing in all age groups in Canada. In particular, these conditions were increasingly prevalent among younger people. Such trends have significant implications, because the presence of risk factors in early and mid life predisposes people to earlier onset of cardiovascular disease and greater potential for life-years lost. ${ }^{11-13}$ Furthermore, early-onset heart disease, hypertension, diabetes and obesity are likely to incur greater consumption of health care resources, because individuals with these conditions may require treatment of greater intensity and longer duration.

We found that an important modifier of the trends in risk factors was income adequacy, a measure of socio-economic status (reflecting disposable household income), which accounts for the size of the family unit. ${ }^{14}$ In addition to having the highest baseline rates of risk factors, lower-income groups also exhibited high absolute increases in risk factors in Canada overall and in individual provinces. The gaps between the highest and lowest income groups in terms of prevalence of hypertension and diabetes also widened progressively over time. We also found that obesity modified the rising burden of both diabetes and hypertension, with both of these conditions increasing most prominently among people with a BMI of 30 or greater. Hypertension was more prevalent among people with a higher BMI, but it increased in all weight groups. Because obe- 
sity can lead to the development of hypertension and diabetes and is a major predisposing factor for early-onset myocardial infarction, ${ }^{15}$ much can be gained by efforts to decrease body weight early in life. Our findings suggest that the rising burden of obesity, diabetes and hypertension could result in future increases in cardiovascular disease, unless widespread efforts are instituted to control and prevent these risk factors.

Reports from other countries, including the United States, appear consistent with our findings for trends examined without stratification by socio-economic status. ${ }^{16,17}$ The Framingham Heart Study investigators reported that the incidence of type 2 diabetes doubled over the past 30 years and the rate of obesity increased more than 3 -fold over the past 5 decades. ${ }^{18}$ Most of the absolute increase in diabetes occurred among obese individuals. ${ }^{19}$ The problem is further exacerbated by reports of the rapid rise of severe obesity (BMI $\geq 40) .{ }^{20}$ Reducing obesity and overweight in the population will likely translate into substantial benefits. However, great efforts are needed to change the current trends, which have been present for decades.

Previous studies of national trends in risk factors have yielded disparate results for examination of data by socio-
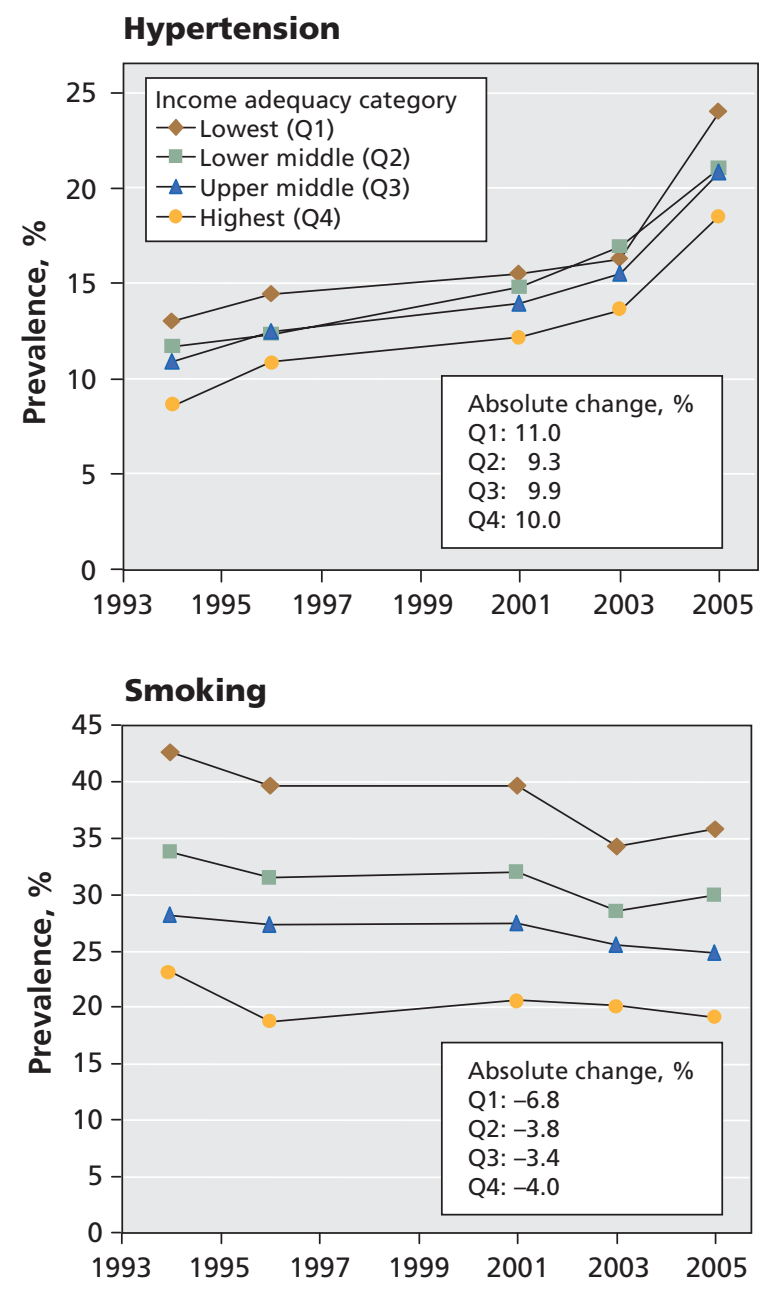

economic strata. In the National Health and Nutrition Examination Survey study in the United States, the prevalence of hypertension decreased in all income groups, smoking decreased selectively among those with high income, and diabetes increased mostly in the lowest-income group. ${ }^{21}$ The prevalence of hypertension also decreased in a Finnish study conducted in 3 regions of that country. ${ }^{22}$ Investigators from the World Health Organization's Multinational Monitoring of Trends and Determinants in Cardiovascular Disease project found that mean blood pressure decreased with a concomitant decrease in rates of coronary events over time. ${ }^{23}$ In contrast, in our study, hypertension increased irrespective of income, and diabetes increased in nearly all income groups (except the highest), whereas smoking decreased in all income groups. The distinct differences in trends between Canada and other nations, including the United States, underscore the importance of examining risk factors in different jurisdictions. Our contrasting results may be due, in part, to the greater screening for conditions such as hypertension and diabetes in a setting with universal access to health care. ${ }^{24,25}$

Increasing prevalence of cardiovascular disease and its pre-

\section{Diabetes}
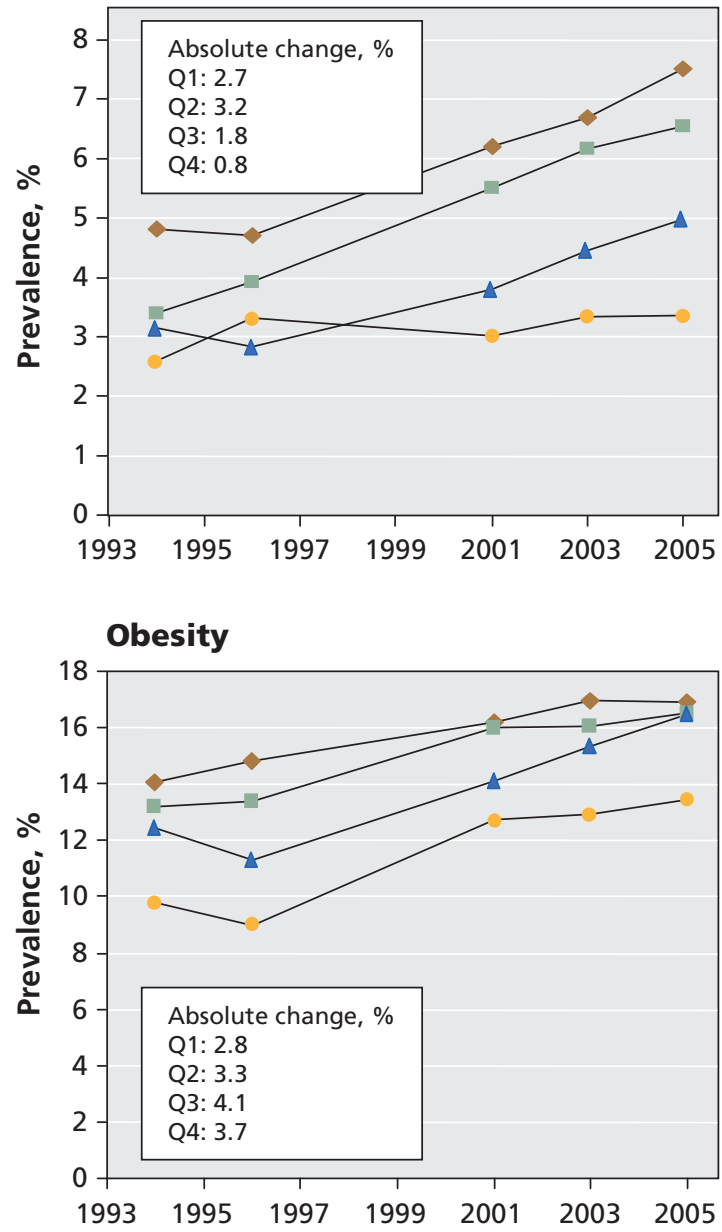

Figure 2: Age- and sex-adjusted prevalence of hypertension, diabetes, smoking and obesity from 1994 to 2005 , stratified by income adequacy category. 
disposing risk factors may be due to rising incidence, enhanced identification ${ }^{26}$ or increased survivorship among those with prior myocardial infarction or coronary disease. ${ }^{27-29}$ The increase in obesity is likely multifactorial and may be due to decreasing physical activity, sedentary lifestyle, obesogenic dietary pattern and sex-related effects (since the rise in obesity was less for women than for men). The increasing prevalence of obesity contributed to the rising rates of hypertension and diabetes. However, it was not the only contributor to those trends: both hypertension and diabetes also increased (albeit to a lesser extent) among overweight and normal-weight individuals. The continuing increase in hypertension in all weight groups suggests that a plateau has not been reached; thus, we anticipate that there remains a large proportion of people in Canada with as-yet-undiagnosed hypertension.

The results of our study have implications for all Canadians, because the surveys were conducted in a representative sample of the Canadian population, including all ethnic groups. Our findings draw attention to risk factors in early adulthood, which predict cardiovascular disease of earlier onset ${ }^{30}$ and which are associated with greater need for health care resources in the last years of life. ${ }^{31}$ Other investigators have projected that the rising prevalence of obesity in the current generation of adolescents will increase the prevalence of coronary artery disease by 5\%$16 \%$ by $2035^{32}$ and may significantly reduce life expectancy in the 21 st century, ${ }^{33}$ a trend that has not been seen for 2 centuries. Enhanced efforts for primary prevention are needed, emphasizing healthy diet and physical activity beginning early in life, which will reduce early-adulthood obesity and diabetes. ${ }^{34-36}$ Although cigarette consumption has declined, smoking rates remain high, which has substantial downstream implications. Early-life smoking increases the risk of vascular disease, lung cancer, pulmonary disease and death from other smokingrelated cancers. ${ }^{37}$ Conversely, cessation of smoking in later life will contribute to a further reduction in acute coronary syndrome events in the future..$^{38}$

\section{Limitations}

A notable limitation of our study was the reliance of the survey data on self-reported risk factors. However, prior studies have suggested that self-reported hypertension correlates well with measured values, particularly in aggregated analyses. ${ }^{39}$ Surveys may underestimate disease conditions such as hypertension, because patients whose blood pressure is controlled may erroneously believe that they are "cured." ${ }^{40}$ However, underreporting of hypertension would probably not affect our results, which included an examination of trends over time. Obesity was also determined from self-reported height and weight. Comparisons of measured and self-reported BMI have suggested that selfreported values may underestimate the true prevalence of obesity by $9 \%$ for men and $6 \%$ for women. ${ }^{41}$ Therefore, obesity may be even more prevalent than our findings suggest. We did not examine trends in lipid concentrations, nor did we specifically report on physical fitness, exercise performed, or the treatment and control of risk factors. Finally, although there was some variability in the specific content areas of the surveys between years, we focused on survey questions and measurements that were obtained consistently over time.
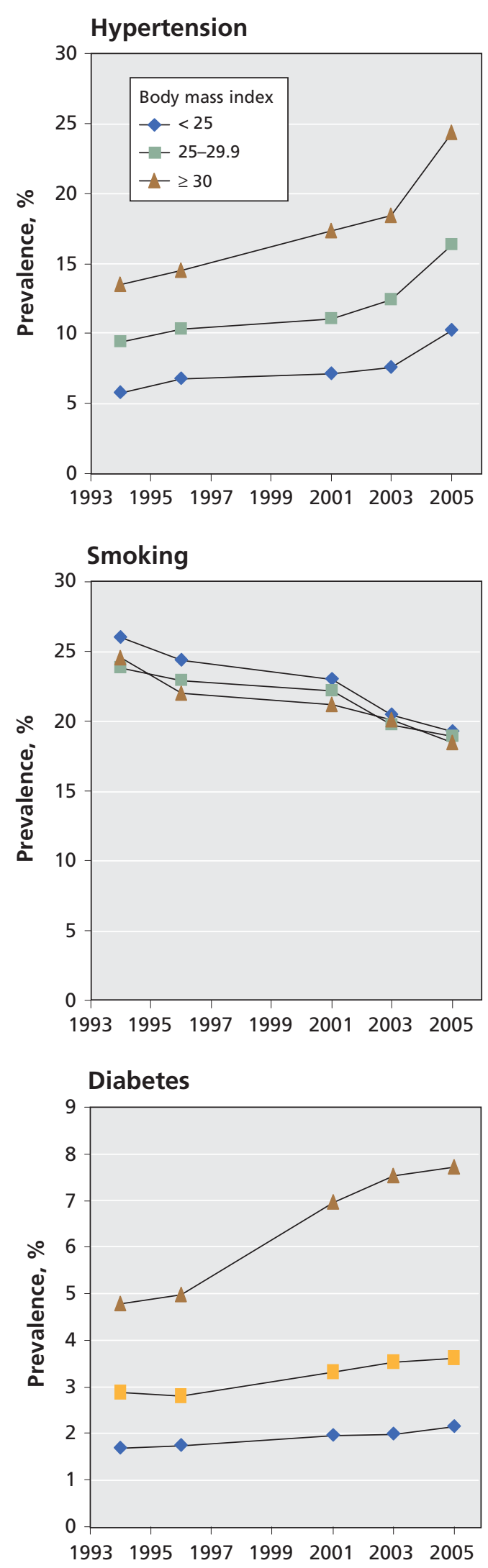

Figure 3: Trends in risk factors, by body mass index category. 
Table 6: Age- and sex-adjusted prevalence of risk factors, for participants aged 20 years and older, by province, from 1994 to 2005 *

\begin{tabular}{|c|c|c|c|c|c|c|}
\hline \multirow[b]{2}{*}{ Province } & \multicolumn{5}{|c|}{ Year; prevalence, \% } & \multirow{2}{*}{$\begin{array}{c}\text { Relative change } \\
\text { from } 1994 \text { to } 2005, \%\end{array}$} \\
\hline & 1994 & 1996 & 2001 & 2003 & 2005 & \\
\hline \multicolumn{7}{|l|}{ Hypertension } \\
\hline Newfoundland and Labrador & 10.1 & 9.3 & 12.0 & 12.5 & 17.5 & 74 \\
\hline Prince Edward Island & 9.8 & 10.3 & 10.5 & 11.2 & 15.3 & 55 \\
\hline Nova Scotia & 12.2 & 13.6 & 12.1 & 13.1 & 17.8 & 46 \\
\hline New Brunswick & 9.6 & 10.7 & 10.9 & 11.9 & 18.4 & 92 \\
\hline Quebec & 7.9 & 8.3 & 9.4 & 10.5 & 13.8 & $74 \dagger$ \\
\hline Ontario & 8.3 & 9.4 & 10.8 & 11.2 & 15.0 & $81 \dagger$ \\
\hline Manitoba & 9.6 & 9.2 & 10.0 & 10.6 & 14.6 & 52 \\
\hline Saskatchewan & 9.8 & 9.0 & 9.3 & 11.0 & 15.1 & 54 \\
\hline Alberta & 7.1 & 8.3 & 9.1 & 10.4 & 14.0 & $98+$ \\
\hline British Columbia & 7.0 & 8.0 & 8.7 & 10.8 & 13.1 & $87+$ \\
\hline \multicolumn{7}{|l|}{ Diabetes } \\
\hline Newfoundland and Labrador & 3.6 & 3.9 & 4.5 & 4.8 & 5.0 & $38 \ddagger$ \\
\hline Prince Edward Island & 3.1 & 2.6 & 3.8 & 3.9 & 4.5 & $48+$ \\
\hline Nova Scotia & 2.9 & 3.6 & 3.9 & 4.0 & 4.7 & $65+$ \\
\hline New Brunswick & 2.3 & 2.6 & 3.8 & 4.0 & 4.2 & $79 \S$ \\
\hline Quebec & 2.5 & 2.6 & 3.1 & 3.3 & 3.7 & $46 \S$ \\
\hline Ontario & 2.5 & 2.6 & 3.3 & 3.5 & 3.6 & $45 \ddagger$ \\
\hline Manitoba & 2.5 & 2.6 & 2.9 & 3.9 & 3.2 & 29 \\
\hline Saskatchewan & 2.4 & 2.3 & 3.0 & 3.5 & 3.6 & $53 \S$ \\
\hline Alberta & 2.5 & 2.2 & 2.9 & 3.0 & 3.2 & $26 t$ \\
\hline British Columbia & 2.2 & 2.4 & 2.9 & 3.3 & 3.3 & $55 \ddagger$ \\
\hline \multicolumn{7}{|l|}{ Smoking } \\
\hline Newfoundland and Labrador & 25.3 & 25.0 & 24.4 & 20.4 & 19.9 & $-21 \dagger$ \\
\hline Prince Edward Island & 26.1 & 27.1 & 23.5 & 19.9 & 18.6 & $-29+$ \\
\hline Nova Scotia & 27.6 & 26.1 & 23.6 & 19.9 & 19.3 & $-30 \S$ \\
\hline New Brunswick & 25.5 & 23.4 & 22.2 & 21.2 & 19.2 & $-25 \S$ \\
\hline Quebec & 28.1 & 27.2 & 24.7 & 21.8 & 20.6 & $-27 \S$ \\
\hline Ontario & 22.7 & 20.8 & 20.5 & 18.5 & 17.3 & $-24 \dagger$ \\
\hline Manitoba & 24.6 & 22.2 & 21.3 & 19.2 & 17.4 & $-29 \S$ \\
\hline Saskatchewan & 25.1 & 24.9 & 23.6 & 20.4 & 20.3 & $-19+$ \\
\hline Alberta & 22.7 & 22.9 & 22.6 & 18.8 & 18.7 & -18 \\
\hline British Columbia & 21.6 & 20.2 & 17.2 & 15.8 & 15.2 & $-30 \ddagger$ \\
\hline \multicolumn{7}{|l|}{ Obesity } \\
\hline Newfoundland and Labrador & 11.6 & 11.6 & 15.1 & 14.9 & 17.4 & $50 \S$ \\
\hline Prince Edward Island & 11.7 & 10.4 & 12.7 & 14.5 & 16.0 & $37 \dagger$ \\
\hline Nova Scotia & 12.5 & 13.8 & 15.0 & 14.5 & 15.0 & $20 \dagger$ \\
\hline New Brunswick & 12.4 & 13.3 & 14.6 & 14.9 & 16.4 & $32 \S$ \\
\hline Quebec & 8.2 & 7.6 & 9.2 & 10.0 & 10.2 & $25 t$ \\
\hline Ontario & 10.2 & 8.7 & 10.8 & 10.8 & 10.9 & 7 \\
\hline Manitoba & 12.0 & 11.0 & 12.7 & 13.2 & 13.2 & 10 \\
\hline Saskatchewan & 11.5 & 12.2 & 13.3 & 14.3 & 14.9 & $30 \ddagger$ \\
\hline Alberta & 8.6 & 8.4 & 11.5 & 11.3 & 11.6 & $35 t$ \\
\hline British Columbia & 7.7 & 7.4 & 8.7 & 8.4 & 9.6 & $25 t$ \\
\hline
\end{tabular}

*Age- and sex-adjusted rates were standardized to 1991 estimates of the Canadian population.

$\S p<0.01$. 


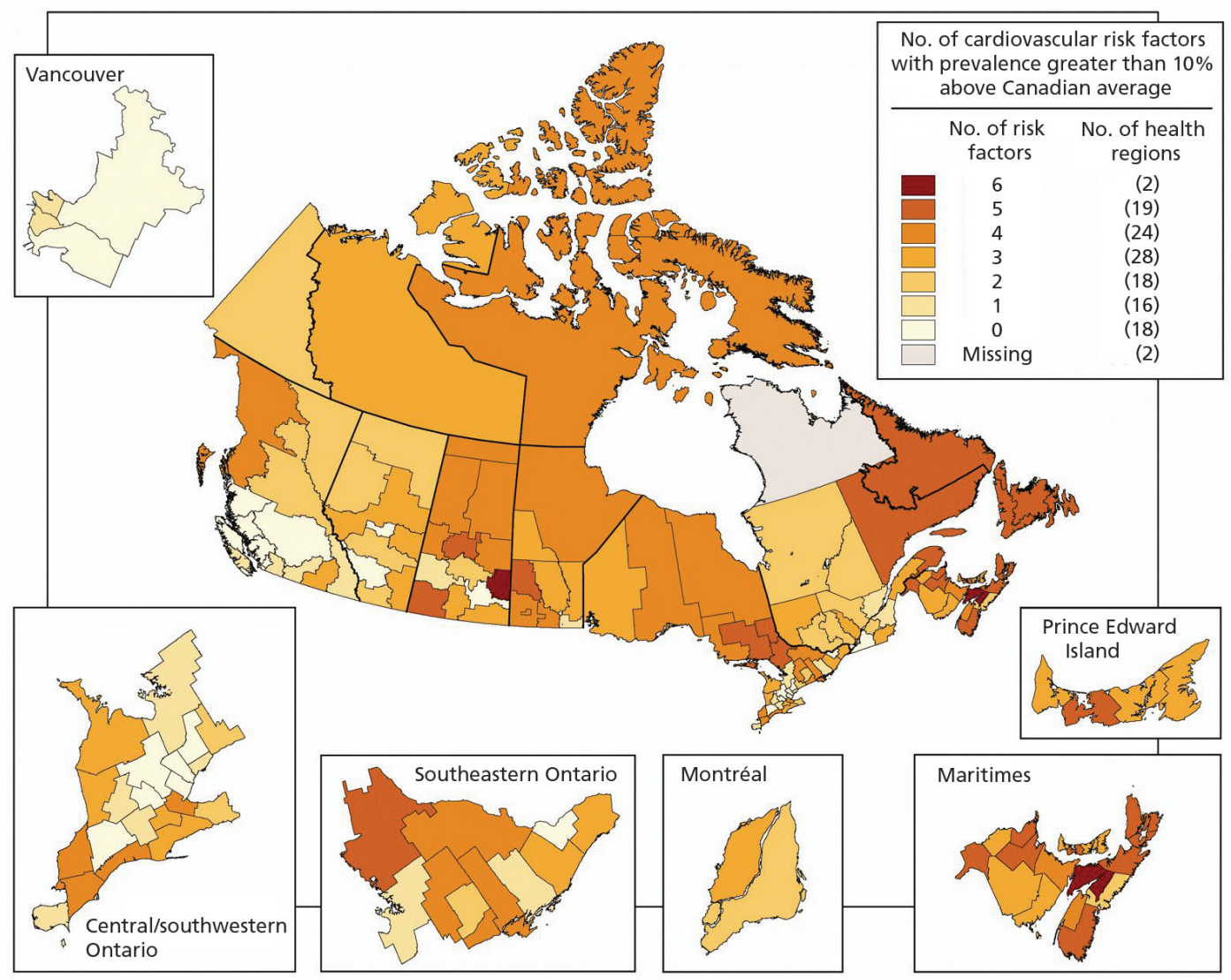

Figure 4: Map of risk factors for cardiovascular disease in Canada. Health regions for which data were available are shown according to the number of risk factors with a prevalence exceeding the national average by at least $10 \%$.

\section{Conclusion}

There is an increasing prevalence of heart disease and risk factors for cardiovascular disease in Canada. In particular, cardiovascular risk factors are increasingly prevalent among younger Canadians, the highest rates being observed among those of lower socio-economic status. Despite the universality of access to health care in Canada, there were widening gaps in the prevalence of hypertension and diabetes between the highest and the lowest socio-economic groups. There is great potential for more cardiovascular disease and worsening disparities in the future unless preventive efforts are directed toward these vulnerable groups. Interventions to encourage healthy eating and exercise and the provision of affordable preventive strategies, such as smoking cessation therapy, to at-risk groups may help to reduce these disparities.

Additional graphs and PowerPoint slides of data from this study are available for presentations at www.ccort.ca/Trends.aspx.

This article has been peer reviewed.

Competing interests: None declared.

Contributors: Douglas Lee, Maria Chiu, Douglas Manuel and Jack Tu contributed to the conception and design of this study and analyzed and inter- preted the data. Karen Tu, Xuesong Wang, Peter Austin, Michelle Mattern, Tezeta Mitiku, Lawrence Svenson, Wayne Putnam and William Flanagan contributed to the data analysis and interpretation. All of the authors contributed to the drafting or revision of the manuscript. All of the authors approved the final version submitted for publication.

Funding: This study was supported by a Team Grant in Cardiovascular Outcomes Research to the Canadian Cardiovascular Outcomes Research Team from the Canadian Institutes of Health Research (CIHR). Douglas Lee is supported by a Clinician-Scientist Award, and Peter Austin by a New Investigator Award, from CIHR. Jack Tu is supported by a Career Investigator Award from the Heart and Stroke Foundation of Ontario and a Canada Research Chair in Health Services Research. The Institute for Clinical Evaluative Sciences is funded by a grant from the Ontario Ministry of Health and LongTerm Care. The opinions, results and conclusions reported in this article are those of the authors and should not be attributed to any of the funding or sponsoring agencies. All decisions regarding the study design, publication and data analysis were made independent of the funding agencies.

\section{REFERENCES}

1. Tu JV, Nardi L, Fang J, et al.; for the Canadian Cardiovascular Outcomes Research Team. National trends in rates of death and hospital admissions related to acute myocardial infarction, heart failure and stroke, 1994-2004. CMAJ 2009;180:1304-9.

2. Rosamond W, Flegal K, Furie K, et al. Heart disease and stroke statistics - 2008 update: a report from the American Heart Association Statistics Committee and Stroke Statistics Subcommittee. Circulation 2008;117:e25-146.

3. Ford ES, Ajani UA, Croft JB, et al. Explaining the decrease in U.S. deaths from coronary disease, 1980-2000. N Engl J Med 2007;356:2388-98.

4. National Population Health Survey (NPHS), cycles 1 (1994-1995) and 2 (1996-1997). 
Ottawa (ON): Statistics Canada (accessed remotely 2008 June 10 to 2009 Jan. 9).

5. Canadian Community Health Survey (CCHS), cycles 1.1 (2001-2001), 2.1 (2003), and 3.1 (2005). Ottawa (ON): Statistics Canada (accessed remotely 2008 June 10 to 2009 Jan. 9).

6. Statistics Canada quality guidelines. 3rd ed. Ottawa (ON): Statistics Canada; 1998. Cat no 12-539-X1E. Available: www.statcan.gc.ca/pub/12-539-x/4194542-eng.pdf (accessed 2009 Apr. 23)

7. Methodology of the Canadian labour force survey. Ottawa (ON): Statistics Canada; 1998. Cat no. 71-526-XPB. Available: www.statcan.gc.ca/bsolc/olc-cel /olc-cel?catno=71-526-X\&lang=eng (accessed 2009 Apr. 23).

8. Canadian Community Health Survey: cycle 1.1. Derived variable (DV) specifications. 2001. Ottawa (ON): Statistics Canada; 2001. Available: https://ozone.scholarsporta .info/bitstream/1873/207/5/cchs2000-2001dv.pdf (accessed 2009 Apr. 23)

9. Health regions 2005 - by peer group. Ottawa (ON): Statistics Canada; 2005. Cat no 82-221-XIE. Available: www.cihi.ca/indicators/2005/en/downloads/HR_by_PG _2005_E.pdf (accessed 2009 Apr. 23).

10. Tanuseputro P, Manuel DG, Leung M, et al. Risk factors for cardiovascular disease in Canada. Can J Cardiol 2003;19:1249-59.

11. Pletcher MJ, Bibbins-Domingo K, Lewis CE, et al. Prehypertension during young adulthood and coronary calcium later in life. Ann Intern Med 2008;149:91-9.

12. Kittleson MM, Meoni LA, Wang NY, et al. Association of childhood socioeconomic status with subsequent coronary heart disease in physicians. Arch Intern Med 2006;166:2356-61.

13. Willcox BJ, He Q, Chen R, et al. Midlife risk factors and healthy survival in men JAMA 2006;296:2343-50.

14. Cairney J, Arnold R. Socioeconomic position. Lifestyle and health among Canadians aged 18 to 64: a multi-condition approach. Can J Public Health 1998;89:208-12.

15. Madala MC, Franklin BA, Chen AY, et al. Obesity and age of first non-STsegment elevation myocardial infarction. J Am Coll Cardiol 2008;52:979-85.

16. Greenlund KJ, Zheng ZJ, Keenan NL, et al. Trends in self-reported multiple cardiovascular disease risk factors among adults in the United States, 1991-1999. Arch Intern Med 2004;164:181-8.

17. Morabia A, Costanza MC. The obesity epidemic as harbinger of a metabolic disorder epidemic: trends in overweight, hypercholesterolemia, and diabetes treatmen in Geneva, Switzerland, 1993-2003. Am J Public Health 2005;95:632-5.

18. Parikh NI, Pencina MJ, Wang TJ, et al. Increasing trends in incidence of overweight and obesity over 5 decades. Am J Med 2007;120:242-50.

19. Fox CS, Pencina MJ, Meigs JB, et al. Trends in the incidence of type 2 diabetes mellitus from the 1970s to the 1990s: the Framingham Heart Study. Circulation 2006;113:2914-8.

20. Freedman DS, Khan LK, Serdula MK, et al. Trends and correlates of class 3 obesity in the United States from 1990 through 2000. JAMA 2002;288:1758-61.

21. Kanjilal S, Gregg EW, Cheng YJ, et al. Socioeconomic status and trends in disparities in 4 major risk factors for cardiovascular disease among US adults, 19712002. Arch Intern Med 2006;166:2348-55.

22. Harald $\mathrm{K}$, Koskinen S, Jousilahti $\mathrm{P}$, et al. Changes in traditional risk factors no longer explain time trends in cardiovascular mortality and its socioeconomic differences. J Epidemiol Community Health 2008;62:251-7.

23. Kuulasmaa K, Tunstall-Pedoe H, Dobson A, et al. Estimation of contribution of changes in classic risk factors to trends in coronary-event rates across the WHO MONICA Project populations. Lancet 2000;355:675-87.

24. Tu K, Chen Z, Lipscombe LL. Prevalence and incidence of hypertension from 1995 to 2005: a population-based study. CMAJ 2008;178:1429-35.

25. Lipscombe LL, Hux JE. Trends in diabetes prevalence, incidence, and mortality in Ontario, Canada 1995-2005: a population-based study. Lancet 2007;369:750-6.

26. Onysko J, Maxwell C, Eliasziw M, et al. Large increases in hypertension diagnosi and treatment in Canada after a healthcare professional education program. Hypertension 2006;48:853-60.

27. Leenen FH, Dumais J, McInnis NH, et al. Results of the Ontario survey on the prevalence and control of hypertension. CMAJ 2008:178:1441-9.

28. Tu K, Chen Z, Lipscombe LL. Mortality among patients with hypertension from 1995 to 2005: a population-based study. CMAJ 2008;178:1436-40.

29. Gregg EW, Gu Q, Cheng YJ, et al. Mortality trends in men and women with diabetes, 1971 to 2000. Ann Intern Med 2007;147:149-55.

30. Power C, Hypponen E, Smith GD. Socioeconomic position in childhood and early adult life and risk of mortality: a prospective study of the mothers of the 1958 British birth cohort. Am J Public Health 2005;95:1396-402.

31. Daviglus ML, Liu K, Pirzada A, et al. Cardiovascular risk profile earlier in life and Medicare costs in the last year of life. Arch Intern Med 2005;165:1028-34

32. Bibbins-Domingo K, Coxson P, Pletcher MJ, et al. Adolescent overweight and future adult coronary heart disease. $N$ Engl J Med 2007;357:2371-9.

33. Olshansky SJ, Passaro DJ, Hershow RC, et al. A potential decline in life expectancy in the United States in the 21st century. N Engl J Med 2005;352:1138-45.

34. Brunner EJ, Mosdol A, Witte DR, et al. Dietary patterns and 15-y risks of major coronary events, diabetes, and mortality. Am J Clin Nutr 2008;87:1414-21.

35. Leitzmann MF, Park Y, Blair A, et al. Physical activity recommendations and decreased risk of mortality. Arch Intern Med 2007;167:2453-60.

36. McKeown NM, Meigs JB, Liu S, et al. Whole-grain intake is favorably associated with metabolic risk factors for type 2 diabetes and cardiovascular disease in the Framingham Offspring Study. Am J Clin Nutr 2002;76:390-8.

37. Kenfield SA, Stampfer MJ, Rosner BA, et al. Smoking and smoking cessation in relation to mortality in women. JAMA 2008;299:2037-47.

38. Juster HR, Loomis BR, Hinman TM, et al. Declines in hospital admissions for acute myocardial infarction in New York state after implementation of a compre- hensive smoking ban. Am J Public Health 2007;97:2035-9.

39. Ezzati M, Oza S, Danaei G, et al. Trends and cardiovascular mortality effects of state-level blood pressure and uncontrolled hypertension in the United States. Circulation 2008;117:905-14

40. Gentleman JF, Tomiak M. The consistency of various high blood pressure indicators based on questionnaire and physical measures data from the Canada Health Survey. Health Rep 1992;4:293-311.

41. Estimates of obesity based on self-report versus direct measures. Ottawa (ON): Statistics Canada; 2008. Cat no 82-003. Available: www.statcan.gc.ca/pub/82-003-x /2008002/article/10569-eng.htm (accessed 2009 Apr. 23).

Correspondence to: Dr. Douglas S. Lee, Institute for Clinical Evaluative Sciences, Rm. G-106, 2075 Bayview Ave., Toronto ON M4N 3M5; fax 416 480-6048; dlee@ices.on.ca

The Canadian Cardiovascular Outcomes Research Team: Jack V. Tu, MD PhD, Institute for Clinical Evaluative Sciences, Sunnybrook Health Sciences Centre, University of Toronto; William Ghali MD MPH, University of Calgary; Louise Pilote MD PhD, Division of General Internal Medicine, McGill University and McGill University Health Centre; Jafna L. Cox BA MD, Division of Cardiology, Dalhousie University, Capital Health; Douglas S. Lee MD PhD, Institute for Clinical Evaluative Sciences, Division of Cardiology, Toronto General Hospital; Karin H. Humphries MBA DSc, Division of Cardiology, University of British Columbia; David Alter MD PhD, Institute for Clinical Evaluative Sciences, Division of Cardiology, St. Michael's Hospital and the Toronto Rehabilitation Institute; Peter C. Austin PhD, Institute for Clinical Evaluative Sciences, Dalla Lana School of Public Health, University of Toronto; Mark J. Eisenberg MD MPH, Divisions of Cardiology and Clinical Epidemiology Jewish General Hospital, McGill University; William M. Flanagan BM, Statistics Canada; P. Diane Galbraith BN MSc, Foothills Medical Centre, University of Calgary; Michelle M. Graham MD, University of Alberta; Ansar Hassan MD PhD, Department of Cardiac Surgery, Saint John Regional Hospital, Atlantic Health Sciences Corporation, Gregory M. Hirsch MD, Department of Surgery, Dalhousie University; Thao Huynh MD MSc, Research Institute of the McGill University Health Centre; Cynthia A. Jackevicius PharmD MSc, Western University of Health Sciences, Institute for Clinical Evaluative Sciences; Helen L. Johansen PhD, Health Analysis Division, Statistics Canada, Department of Community Medicine and Epidemiology, University of Ottawa; Merril L. Knudtson MD, Libin Cardiovascular Institute of Alberta; Dennis T. Ko MD MSc, Division of Cardiology, Schulich Heart Centre, Sunnybrook Health Sciences Centre, University of Toronto, Institute for Clinical Evaluative Sciences; Michael P. Love MB ChB MD, Department of Medicine, Queen Elizabeth II Health Sciences Centre, Dalhousie University; Douglas G. Manuel MD MSc, Ottawa Health Research Institute; Colleen M. Norris, RN PhD (Epid), Faculties of Nursing and Medicine, University of Alberta; Wayne Putnam MD, Department of Family Medicine, Dalhousie University; Stéphane Rinfret MD MSc, Institut Universitaire de Cardiologie et de Pneumologie de Québec, Université Laval; Michael J. Schull MD MSc, Institute for Clinical Evaluative Sciences, Department of Medicine, University of Toronto; Derek Y. So MD, University of Ottawa Heart Institute; Therese A. Stukel PhD, Institute for Clinical Evaluative Sciences; Lawrence W. Svenson BGS, Surveillance and Environmental Health, Alberta Health and Wellness, School of Public Health, University of Alberta; Christopher R. Thompson MD CM, St. Paul's Hospital, University of British Columbia; Karen Tu MD MSc, Institute for Clinical Evaluative Sciences, Department of Family and Community Medicine, University of Toronto; and Nancy A. Walton PhD, Daphne Cockwell School of Nursing Chair, Research Ethics Board, Ryerson University 